\title{
OCEANOGRAPHY
}

\section{Power of pull}

\section{As the complex interplay of forces in the ocean responds to climate change, the dynamics of global ocean circulation are shifting.}

\section{Martin Visbeck}

Global climate change is edging the oceans towards a daunting future of sealevel rise, an increase in dissolved carbon dioxide and in acidity, reduced subsurface oxygen, and the possible loss of marine biodiversity and ecosystem functions. In all of this, large-scale ocean circulation plays a central role. Aside from affecting and to some extent being affected by these changes, the oceans are pivotal in global climate regulation. Any big shifts in this complex system present a considerable challenge to science and society.

In large-scale ocean circulation, often compared to a global conveyor belt, warm surface waters flow northwards from the equatorial Atlantic, giving up heat to the atmosphere. The cold, dense water sinks in the Greenland and Labrador Seas and returns to the Southern, Indian and Pacific Oceans as deep currents. This global overturning circulation is key to climatic stability because it contributes to more than half of the global ocean heat transport and allows many gigatonnes of $\mathrm{CO}_{2}$ to be stored in vast amounts of deep ocean water, out of contact with the atmosphere. Global-scale differences in water density - built at the sea surface through solar heating, clouds and rain, and eroded by internal mixing caused by winds and tides - drive the movement of water. But what determines the vigour of global circulation: the 'push' of dense waters to depth in the polar regions, or the 'pull' of mixing those waters upwards throughout the ocean basins?

At Kiel University, Germany, in the late 1980s, we were focused on push - the sinking of cold, salty, dense surface waters in the North Atlantic, known as deep-water formation. We felt we were making exciting progress in understanding what drives the ocean conveyer belt. What we didn't realize then was that pull - the slow upwelling that arises from ocean mixing - was a crucial piece of this giant marine puzzle.

Push plays an obvious part in deep ocean circulation: if a deep, dense water reservoir grows in volume, its spread into all deep ocean basins will accelerate. But how does the water get from the surface to the depths? We began to see intriguing new direct measurements of vertical flows, capable of mixing fluid 'parcels' down to depths of 1 to 2 kilometres within a few hours, along with the first high-resolution computer models (basically upsidedown cloud convection models) that could simulate this process in vivid detail. We learned that this deep convective mixing occurs sporadically, when high surface salinities come together with enough cold and windy winter days to make the surface water dense enough to let it plunge to the

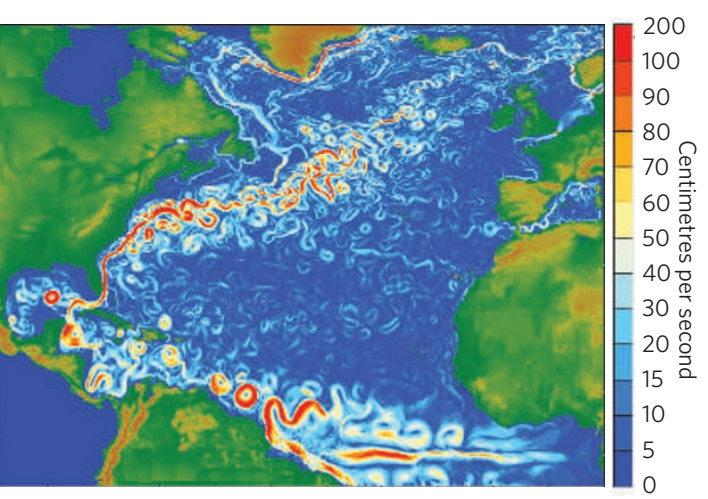

Simulation of near-surface ocean current speeds.

depths of the ocean. And it turned out that convection is also confined to a few key regions in the centre of the Greenland and Labrador Seas in late winter.

Push is also a key player in carbon sequestration. When surface and subsurface layers in those seas become cold and dense enough to cause intense vertical mixing, this water, replenished from the atmosphere with high levels of oxygen, $\mathrm{CO}_{2}$ and other substances, is transferred to the depths. From there, a complex set of deep currents, most of which hug the western sides of the ocean basins, spreads the newly 'ventilated' water around the world.

Where does that leave pull? It took until 1994 for me to see its true importance. Confronted with simulations of one of the first global ocean circulation models, devised by Robbie Toggweiler at the Geophysical Fluid Dynamics Laboratory in Princeton, New Jersey, I was shocked. The model showed that artificially increasing wind speeds over the Southern Ocean enhanced deep upwelling, and the North Atlantic responded with an increase in overturning circulation.

Then I remembered Johan Sandström. In 1908, the Swedish oceanographer elegantly demonstrated how heating at depth is vital for maintaining a globalscale circulation in tank experiments. (After all, boilers are generally installed in basements so that the hot, less dense water flows upwards into a house's radiators.) To keep a density-driven ocean circulation going, you need vertical mixing of warmer waters into the ocean depths, which makes deeper water less dense, prompting upwelling - that is, pull.

Much remains to be discovered about ocean mixing. We do know it is largely driven by the wind and tide. Wind, for instance, creates surface waves that stir the upper layers of the ocean directly, and also induces surface friction that generates large-scale, deepreaching currents. In their turn, these currents can create turbulent mesoscale eddies - ringlike flows with a radius of 10 to 100 kilometres. When wind- or tide-driven currents interact with undersea topography, steep subsurface internal waves are generated, some of which break just like waves on a beach to help mix density layers at depth. Tropical hurricanes and nekton - the huge schools of krill and small fish that create 'biological stirring' as they swim - are other possible sources of ocean mixing.

What does the future hold? By century's end, warming will cause more rainfall in polar regions, diluting the oceans along with meltwater from glaciers and the Greenland ice sheet. All this will lower ocean salinities and, together with warmer winter temperatures, reduce deep convection: the push will weaken. Current climate models predict that the Atlantic overturning will slow by $30 \%$.

But over the longer term, shifts in pull will matter. Those same models suggest increased winds over the Southern Ocean and the possibility of stronger hurricanes. Both would boost ocean mixing and could, crucially, offset the trend towards slower circulation. More speculative is the role of any change in nutrient availability, which would affect the abundance of nekton and thus biological stirring. Global ocean observations, improved ocean models, smart brains and a multidisciplinary approach will all be needed to advance this frontier of science.

Martin Visbeck is at the Leibniz Institute of Marine Sciences at the University of Kiel, Düsternbrooker Weg 20, 24105 Kiel, Germany. 